\title{
A SAÚdE PÚBLICA COMO CAMPO dE INVESTIGAÇÃO INTERDISCIPLINAR E A QUESTÃO METODOLÓGICA.
}

Augusta Thereza de Alvarenga*

Resumo: $O$ presente ensaio procura identificar as características básicas da Saúde Pública como campo de investigação interdisciplinar e ressaltar a relevância da consideração de questões metodológicas pelo pesquisador que com elas se defronta consciente ou inconscientemente. Diferenciando as concepções de metodologia teórica e de metodologia da técnica o texto busca mostrar, por um lado, como os fundamentos de naturezas ontológica, epistemológica e lógica encontram-se presentes no trabalho científico articulando os vários níveis presentes no processo de investigação. Por outro, como a metodologia, como disciplina metateórica, tem como objetivo fundamentar as teorias e os métodos e as técnicas de pesquisa que o cientista emprega como instrumental. Procura colocar, outrossim, como a Saúde Pública se inscreve no conjunto das Ciências Naturais, Ciências Sociais e Ciências Formais e o caráter interdisciplinar do campo que dai decorre. Trata, finalmente, dos desafios metodológicos que se apresentam ao investigador preocupado não somente em aplicar metodologias típicas dos paradigmas de investigação vigentes, mas sobretudo em responder às necessidades de avanço do conhecimento que o campo requer tomando como objeto de estudo as novas questões que a este se apresentam e que se colocam à margem da "ciência normal".

\footnotetext{
* Professora Doutora do Departamento de Saúde Materno-Infantil da Faculdade de Saúde Pública da Universidade de São Paulo.
} 


\section{O LUGAR DAS QUESTÕES METODOLÓGICAS NA}

\section{INTERFACE CIÊNCIA E FILOSOFIA}

A reflexão acerca da Saúde Pública como campo de investigação interdisciplinar coloca relevantes questōes metodológicas que não se circunscrevem exclusivamente ao campo da Filosofia da Ciência, mas igualmente ao campo da ciência na medida em que o pesquisador, em diferentes niveis, com elas se defronta, consciente ou inconscientemente, nos vários processos de investigação que empreende.

Entendida como atividade humana organizada, sistematizada, que emprega uma dada racionalidade, a atividade científica encerra um determinado tipo de experiência diferente mas não negadora, segundo WARTOFSKY (1976), daquela vivida pelo senso comum*. Tal atividade se dá sobre determinados objetos gerando como produto um texto, um discurso cientifico, composto de argumentos, enunciados e conceitos que manifestam dado tipo de conhecimento por se inscreverem em determinada perspectiva não somente teórica, mas teóricometodológica.

Caracterizada por muitos autores, notadamente pelos de tradição positivista", como um tipo de conhecimento "objetivo" e "neutro", em função de determinadas regras metodológicas tomadas do campo das ciências naturais como modelo de cientificidade, essa modalidade de pensamento filosófico procura colocar a campos do conhecimento como, por exemplo, o das ciências sociais,

\footnotetext{
" Vale notar que este é um dos pontos controversos presente na literatura especializada que ve a relação entre conhecimento científico e conhecimento do senso comum ora como continuidade, ora como ruptura.

* Para uma visão geral dos principios positivistas norteadores da atividade científica vejase, por exemplo, SKOLIMOWSKI (1983).
} 
questões epistemológicas que se referem ao próprio estatuto científico das mesmas. Neste contexto de grandes polêmicas apresentam-se questões tais como a da universalidade do método científico aplicável a todas as ciências, a do reducionismo teórico e metodológico, a da ruptura ou não do conhecimento cientifico com o conhecimento do senso comum, a da concepção de racionalidade cientifica, além daquelas relativas especificamente à objetividade e à neutralidade cientifica. Diante da relevância dessa gama variada de problemas não somente filósofos da ciência, mas também cientistas que não se propõem, de maneira exclusiva, a empregarem "paradigmas de investigação" consagrados pela "ciência normal" (KUHN, 1975) das respectivas áreas de conhecimento, passam com eles a se ocupar.

Se ao campo das Ciências Sociais e Humanas tais problemas se colocam o mesmo se dá com o campo da Saúde Pública ou Coletiva, cuja inserção como área de conhecimento não se circunscreve ao campo das ciências naturais, mas igualmente ao campo das ciências humanas. Nesse sentido o que se coloca é que a problemática deste, além de ampliar-se, torna-se complexa por apresentar especificidades em relação a interdisciplinariedade que o caracteriza.

Assim, diferentemente das Ciências Sociais que se caracterizam, segundo BRUYNE (1882), como campo pluri e interdisciplinar basicamente pelo fato de não ser passivel de ser englobada ou reduzida a uma única disciplina, o campo da Saúde Pública, além deste aspecto, enfrenta a questão das naturezas biológica, social e psicológica de seu objeto, os processos de saúde-doença coletivos, que desafia seu tratamento.

Na medida em que o contexto da metodologia da ciência, que lida com tais problemas, coloca-se necessariamente, no interior da relação ciência e filosofia, uma questão metodológica básica que se apresenta para o conhecimento cientifico 
é o da diferença teórico-filosófica existente entre "metodologia teórica" e "metodologia da técnica", dadas as especificidades e relevância que tais metodologias apresentam nos processos de investigação.

Isto porque, ao relacionar-se, de maneira essencial, com determinados fundamentos "metateóricos" de natureza ontológica, epistemológica e lógica essas metodologias, inscritas no interior dos sistemas teóricos e tecnológicos, adquirem características próprias mediando e encerrando, diferentemente, abordagens oriundas deste primeiro nível de análise. Tais enfoques referem-se, segundo OLIVEIRA FILHO (1976), às concepções ou correntes analítica, hermenêutica, dialética e pluralista, esta última por apresentar relações triádicas ou diádicas entre as anteriores.

Quando reproduzidas e presentes no interior dos "sistemas teóricos", tais correntes expressam-se, por exemplo o caso das Ciências Sociais (OLIVEIRA FILHO, 1976), como concepções teórico-metodológicas de orientação funcionalista, estruturalista, compreensiva (ou hermenêutica), etnometodológica, existencial, dialética, além do empirismo sociológico. No campo da Biologia apresentam-se como clássicas as explicações mecanicista ou reducionista (mecanicismo), composicionista ou funcionalista (organicismo), histórica ou genética (evolucionismo), além das teleológicas ou hermenêuticas (vitalismo)". Neste nível o instrumental básico disponível ao cientista consiste nas hipóteses, "leis", conceitos e teorias próprias de cada campo e de tipos de abordagens.

Constituindo-se num conjunto de pressupostos racionais presentes tanto no interior dos "sistemas teóricos", quanto no dos "sistemas tecnológicos", tais

\footnotetext{
* Para uma explicitação das correntes específicas do campo da biologia consulte-se, por exemplo, obra de AYALA \& DOBZHANSKI (1983). 
fundamentos* - ontológicos (que versam sobre a natureza do objeto), epistemológicos (que se referem às questões presentes na relação entre sistema teórico/tecnológico e objeto de investigação) e lógicos (que tratam da coerência e adequação da linguagem científica) - pertencem, assim, a um nível superior de linguagem denominado "sistema metateórico" porque relativo ao âmbito da filosofia da ciência. Desse modo, embora apresentem-se como norteadores de processos de investigação científica, encontram-se, muitas vezes, inconscientes para o investigador, notadamente para aqueles preocupados apenas com o que KUHN (1975) nomeia como "Ciência Normal".

A articulação entre esses diferentes niveis presentes no processo de investigação é uma das preocupações de OLIVEIRA FILHO (1976) quando apresenta seu esquema de reconstruções metodológicas de processos de investigação social conforme pode ser visualizado, a seguir, na figura 1.

\footnotetext{
" Como texto de entrada para a análise de tais fundamentos veja-se obra de WARTOFSKY (1976), vol. 1, cap. 1.
} 
FIGURA 1 - RECONSTRUÇÕES METODOLÓGICAS DE PROCESSOS DE INVESTIGAÇÃO SOCIAL.

INSTRUMENTAL DE ÉPOCA

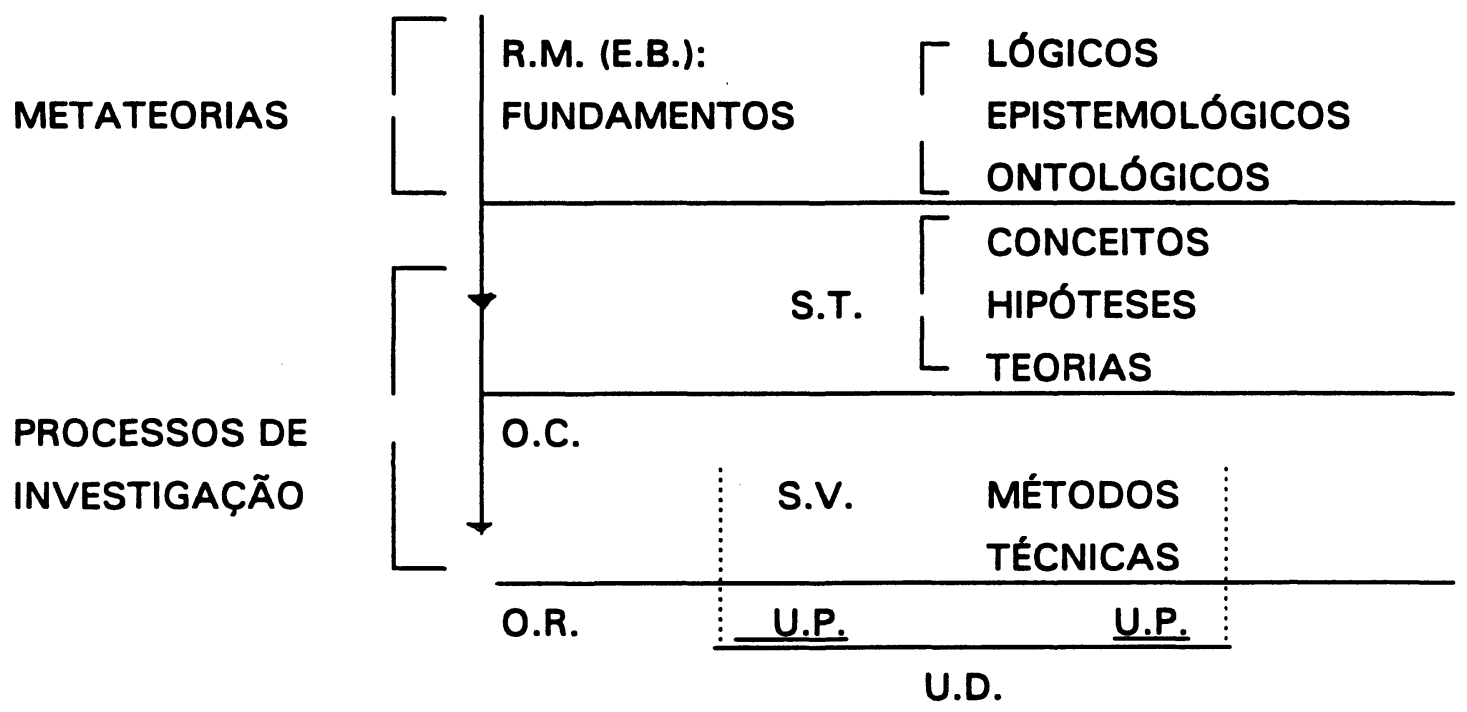

FONTE: OLIVEIRA FILHO (1976)

\section{LEGENDA:}

R.M. = RECONSTRUÇÕES METODOLÓGICAS

S.V. = SISTEMA DE VERIFICAÇÃO

E.B. = ESQUEMAS-BASE

O.R. = OBJETO REAL

S.T. = SISTEMA TEÓRICO

U.P. = UNIVERSO DE PESQUISA

O.C. = OBJETO CONSTRUIDO

U.D. = UNIVERSO DE DISCIPLINA 
Vale observar que neste texto o Professor José Jeremias de OLIVEIRA FILHO (1976) objetiva basicamente estabelecer uma estratégia de trabalho em "Metodologia Teórica" das Ciências Sociais diferenciando a esfera da pesquisa científica da esfera da pesquisa metodológica. Na primeira o cientista dispõe, para sua atividade, de sistemas teórico (S.T.) e de verificação (S.V.), além de universos de pesquisa (U.P.) e universo de disciplina (U.D.). Na segunda o metodólogo, ou filósofo da ciência", possui como recurso de análise dado "Sistema Metateórico" constituido por esquemas-bases (E.B.) relativos não somente aos diferentes fundamentos ontológicos, epistemológicos e lógicos, mas também às concepções analítica, hermenêutica, dialética e pluralista que orientam tais esquemas.

A relevância do texto apresentado por OLIVEIRA FILHO (1976) para a presente reflexão consiste no fato de o referido autor procurar demonstrar que a razão que se exerce na atividade científica ocorre numa interação entre níveis de conhecimento científico tendo a Metodologia como disciplina "metateórica" o objetivo de fundamentar as teorias e os métodos e técnicas de pesquisa social. Nesse sentido os enunciados desse nivel metateórico compõem os argumentos que tem por função a crítica e a justificação possibilitadoras das decisões que permitem ao cientista optar entre hipóteses, conceitos e teorias ou entre "métodos e técnicas" ${ }^{\star \star \star}$ de pesquisa alternativos.

* Para este autor o conceito de Metodologia é sinônimo, neste contexto, de Filosofia da Ciência (termo empregado pela tradição inglesa), de Teoria do Conhecimento (tradição alemã) e de Epistemologia (tradição francesa).

* É importante destacar a diferenciação conceitual e de nivel que OLIVEIRA FILHO (1976) faz, portanto, entre "Metodologia" e "Métodos e Técnicas" de investigação. Afirma, por exemplo, que no processo de investigação no campo das ciências sociais as relações entre sistema teórico (ou lingüistico) com os eventos sociais (as entidades sociais concretas) são realizadas através da tecnologia da pesquisa social (os métodos e as técnicas). 
Assevera, portanto, que sempre que o cientista social - com o qual trabalha - pretenda argumentar a adoção ou rejeição de conceitos ou teorias proferirá enunciados metateóricos. Assim, tal cientista, ao exercer a crítica e a justificação anunciará, através ou não de definições explícitas, os pressupostos filosóficos, epistemológicos e ontológicos, ou lógicos, que fundamentam os processos de investigação social. Entende, desse modo, que a questão metodológica nas Ciências Sociais reflete a diversidade de enfoques com que se tem colocado os seus problemas à reflexão científica em todos os seus níveis.

\section{A SAÚDE PÚBLICA COMO CAMPO DE INVESTIGAÇÃO INTERDISCIPLINAR}

A colocação de questões metodológicas à reflexão científica no campo da Saúde Pública é tema sugestivo pelas características que o mesmo apresenta e ganha especial relevância nas últimas décadas, sobretudo a partir da discussão presente na literatura especializada, sobre a pertinência de esquemas de referência teórico-metodológicos para a abordagem do processo saúde-doença destacandose, como reflexões clássicas, as obras de BREILH \& GRANDA (1980) e LAURELL (1982).

Se no campo das Ciências Sociais e Biológicas a tradição teórica pode firmar-se em termos de diferentes tendências teórico-metodológicas, o mesmo não sucedeu no campo da Saúde em geral, e da Saúde Pública ou Coletiva em particular, aonde a corrente de pensamento analítica apresenta-se como tendência dominante e paradigmática na abordagem do processo saúde-doença, mais propriamente falando, processo saúde-doença-morte. Da mesma forma, na análise da Organização e Administração de Serviços e processos de intervenção é a abordagem funcionalista, em suas diferentes vertentes, notadamente a da análise 
de sistemas, que ganha maior expressão no campo. Somente na abordagem das Políticas de Saúde e da Reforma Sanitária Brasileira pode-se observar a predominância de outras modalidades de enfoques $e$, mais recentemente, na análise da questão dos "serviços".

Desse modo, a despeito do esforço de autores como Juan Cesar GARCIA (1983) para mapear o campo da Saúde em termos das correntes de pensamento nele presentes, o fato a considerar é o de que a maioria das iniciativas particulares não foi suficiente para marcar uma tradição teórico-metodológica diferenciada em termos de tendências de análise do processo saúde-doença-morte, área na qual a questão da interdisciplinariedade ganha relevo mas enfrenta grandes obstáculos, notadamente de natureza epistemológica.

Esta característica faz o campo da Saúde Pública ou Coletiva diferenciar-se, por exemplo, do campo das Ciências Sociais. Para BRUYNE (1982, p. 26) cada disciplina desse campo inter e pluridisciplinar como, por exemplo, a Sociologia, a Psicologia, a Etnologia, a Economia, "não deve visar o conjunto do espaço epistêmico das ciências do homem, mas delimitar - metodologicamente um campo de análise, um aspecto particular desse espaço". Isso porque, para este autor, o trabalho científico diz respeito a domínios especializados o que torna problemático a busca da unidade da ciência. Considera que a ciência se "constitui muito mais em um campo de heterogeneidade no qual disciplinas parcelares tentam se articular umas às outras do que um edifício no qual a totalização do saber se realizaria progressivamente segundo os votos do positivismo". Entende, pois, que se as disciplinas científicas "são parcelares, são também abertas, constantemente questionando, sempre em busca de novos métodos, de novos conceitos, de novos meios de investigação e de verificação". Com base no pensamento de KAPLAN (1964, p. 27) conclui que, consequentemente, não existe também um método científico porque "...se uma definição do método científico fosse bastante específico 
para ter alguma utilidade em metodologia, ela não seria suficientemente geral para abarcar todos os procedimentos que os cientistas podem eventualmente chegar a considerar úteis".

O aspecto básico a considerar no campo da Saúde Pública é o fato de o mesmo, diferentemente das Ciências Sociais, não se constituir de um conjunto de disciplinas científicas parcelares, próprias do campo, capazes de abarcar os diferentes problemas de saúde que o mesmo apresenta e de oferecer abordagens alternativas de análise.

Conta, ao contrário, em termos de tradição, basicamente com o concurso, para a análise do processo saúde-doença-morte, da abordagem epidemiológica clássica de orientação tipicamente analítica e "biologicista". Em função disso apresenta limites para a apreensão da dimensão social de tal processo por operar uma redução da mesma ao buscar integrá-la no interior de tal esquema teórico-metodológico. Como tendência oposta e apontando esses limites de análise, busca firmar-se a chamada "Epidemiologia Crítica"* que procura incorporar ao estudo do processo saúde-doença a perspectiva teórico-metodológica do materialismo histórico que "importa" do campo das Ciências Sociais tendo em vista uma nova concepção ontológica da natureza de tal processo.

Importante aspecto, revelador da força de tal tradição, é o fato deste paradigma clássico de investigação epidemiológica buscar identificar-se como abordagem única do processo saúde-doença-morte chegando, na leitura dos seus seguidores, a confundir-se com a Epidemiologia enquanto "disciplina" e área de

\footnotetext{
* Vale lembrar que é em função de tais limites à apreensão do social por parte da chamada "Epidemiologia Clássica ou Tradicional" que esta nova abordagem, mais adequadamente nomeada como "Epidemiologia Crítica", emerge na década dos 80 , caracterizada como "Epidemiologia Social".
} 
conhecimento no campo da Saúde Pública ou Coletiva. Coube, assim, à chamada "Epidemiologia Crítica", abrir espaço para a discussão desta área como disciplina que comporta diferentes vertentes teórico-metodológicas. Nesse sentido, largo é o caminho metodológico a ser percorrido no campo da Saúde na medida em que diferentes concepções ontológicas acerca da natureza do objeto colocam desafios de natureza epistemológica tanto em nivel do instrumental teórico de análise (novos conceitos, hipóteses e teorias), quanto do instrumental tecnológico (novos métodos e técnicas de investigação). Igualmente relevantes são os desafios metodológicos relativos a novos meios de "verificação" do conhecimento científico, "confirmação" de hipóteses e "falseamento" de teorias.

Se tais questões se apresentam em relação à Epidemiologia, tradicionalmente caracterizada no campo da Saúde como típica área de conhecimento, tendência diferenciada observa-se na área dos Serviços de Saúde, comumente caracterizada como típica área técnica de intervenção. Muito embora o "enfoque sistêmico" e o "planejamento normativo" tenham se firmado como estratégias (técnicas) nas áreas do Planejamento e Administração de Serviços, a partir dos anos 80 , com a implantação do processo de Reforma Sanitária diferentes abordagens teórico-metodológicas do campo das Ciências Sociais podem ser observadas na análise de tal processo, assim como na de Políticas de Saúde e de Planejamento, destacando-se, sobretudo, o denominado "Planejamento Estratégico". Desse modo, esta passa a apresentar-se como importante área de conhecimento e o processo de intervenção como objeto de estudo.

Assim, se para a "Epidemiologia Crítica" a tarefa de firmar-se no campo da Saúde Pública em geral, e na área da Epidemiologia em particular, apresenta-se

\footnotetext{
" Como texto de entrada à questão das teorias para a verificação da "verdade" ou "falsidade" do conhecimenio veja-se, por exemplo, obra de EWING (1984), capítulo 3. Vale lembrar ao leitor que tal questão ganha amplo desdobramento na literatura especializada em relação às teorias "confirmacionista" e "falsacionista" do conhecimento.
} 
como tarefa árdua e desafiadora, o mesmo não ocorre com as novas propostas de políticas e de planejamento em saúde decorrentes de novas abordagens teóricometodológicas. $O$ que tais fatos revelam $\dot{e}$, fundamentalmente, a natureza interdisciplinar do campo que, em função de sua diversidade, abre amplas perspectivas para a presença de várias disciplinas e tendências na análise dos problemas que apresenta.

Esta natureza interdisciplinar do campo melhor se evidencia quando se procura definir as características básicas de uma disciplina científica. Para tanto, a análise que WHITE (1974) faz da História como disciplina, ou interdisciplina científica, em seu artigo sobre "A Explicação Histórica” é bastante sugestiva.

Entendendo a questão da explicação como "uma constelação de afirmações" (p. 441) WHITE (1974) passa, em seu artigo, a indagar não somente acerca da existência de explicações históricas mas em que termos estas se diferenciariam de outras modalidades de explicações tais como as físicas, químicas, biológicas e, sobretudo, sociológicas.

Tal reflexão é bastante rica e permite ao leitor apreender em que termos uma disciplina, constituida de vários esquemas teórico-metodológicos geradores de explicações acerca do objeto que lhes é próprio, pode ser definida e caracterizada.

No tratamento que faz do tema WHITE (1974, p. 443) afirma que as teorias pertencentes a determinada disciplina científica podem ter, cada uma, "suas afirmações divididas em duas classes: as afirmaçōes das disciplinas pressupostas pela teoria e as afirmações especificas da teoria". Ao lado destas colocam-se os termos lógicos sempre presentes, o que significa dizer que a lógica é pressuposta por todas as ciências empíricas e que precede a parte de explicações especificamente física, química, biológica, sociológica ou histórica, por exemplo. 
Em relação a esta segunda classe de termos no campo da História afirma: "se procedendo empiricamente, examinarmos obras históricas para tentar determinar quais os termos que são específicos da história encontrar-nos-emos num pântano, sobretudo por causa do número de termos vindos de outras ciências" (p. 446).

Buscando exemplificar tal assertiva declara que a história "pressupõe a física na medida em que refere tempos e lugares e subentende a verdade das leis físicas; igualmente pressupõe a física na medida em que procura assegurar tantas verdades físicas singulares quantas as suscetiveis de contribuir para uma explicação dos fatos especificamente históricos. A história pressupõe também [continua ele] ciências como a química e a biologia. Com efeito parece quase impossível limitar o número de ciências que a história de facto pressupõe" (p. 450). Prossegue ainda dizendo que "a história pressupõe [também] todas as ciências que se ocupam do comportamento intencional humano. A dificuldade consiste, na realidade, em dizer onde é que elas acabam e onde começa a história. Por outras palavras, os termos específicos das ciências que se ocupam do comportamento humano intencional parecem tão característicos da história que nos é impossível dizer se eles são termos de uma ciência pressuposta ou se são específicos da própria história". Assim, para ele, "se faz parte dos objetivos do historiador dar uma imagem da estrutura social e do desenvolvimento de uma dada sociedade, não se distinguirão então das sociológicas as proposições históricas. $\bigcirc$ mesmo vale para as explicações históricas e sociológicas" (p.451).

A despeito de tais limites o que WHITE (1979,p.444) coloca como questão e hipótese fundamental é o fato de que determinada explicação será ou não histórica na dependência "de ela conter ou não, de modo essencial, termos específicos históricos". 
Trazendo tal reflexão para o campo da Saúde Pública a primeira indagação seria, ao que parece, a da existência ou não de explicações de saúde pública aos problemas de saúde. Tal questão permite evidenciar, de imediato, a característica básica do campo na medida em que o mesmo pode ser pensado, na realidade, somente como uma ampla área empirica passivel de ser explorada por diferentes disciplinas científicas.

Nesse sentido, embora satisfaça a condição ontológica para caracterizar-se como uma disciplina, uma vez que possui nos processos saúdedoença-morte coletivos, um objeto concreto, na sua diversidade de problemas, persiste o fato de não satisfazer a segunda condição, a lingüistica, por não possuir um aparato conceitual autônomo, isto é, um sistema teórico gerador de explicações dos vários problemas que seu objeto comporta.

Neste contexto, a própria indagação acerca da Epidemiologia enquanto disciplina científica do campo encontra espaço para discussão na medida em que, com o aparato conceitual existente, a mesma pressupõe, ao que parece, considerável proporção de conceitos de disciplinas pertencentes ao campo das Ciências Naturais e também Humanas, notadamente a Geografia (caso da Epidemiologia Clássica) e do campo das Ciências Sociais (caso da Epidemiologia Crítica). Em relação à questão do instrumental teórico-metodológico para o tratamento das questões relativas à Administração de Serviços, Políticas de Saúde e de Planejamento em Saúde a contribuição das Ciências Sociais tem sido fundamental.

A reflexão de como o campo da Saúde Pública ou Coletiva relaciona-se com os critérios definidores de uma disciplina científica pode ser ampliada quando se busca considerar como tal campo se inscreve no coniunto das demais ciências e como a questão da condição metodológica ai se coloca. 
Nessa linha de preocupação as colocações de OLIVEIRA FILHO (1987) trazem contribuição. Trabalhando com uma classificação triádica* das ciências, ou seja, Ciências Naturais, Ciências Sociais e Ciências Formais, compreendendo esta úitima a lógica e a matemática, afirma que "a cada uma destas disciplinas, com nível mais abstrato da reflexão científica corresponderá uma metodologia das ciências naturais, metodologia das ciências sociais e metodologia das ciências formais" (p. 2).

Para exemplificar a respeito das diferenças e interações entre as várias metodologias e suas respectivas regras utiliza o diagrama de Venn-Euler conforme o ilustrado, a seguir, na figura 2.

\footnotetext{
* Alguns filósofos da ciência como Karl POPPER (1972) trabalham com uma concepção diádica de ciência. Para este a mesma é classificada como ciências empíricas e ciências formais.
} 
FIGURA 2 - CLASSIFICAÇÃO TRIÁDICA DAS CIÊNCIAS, SEGUNDO CRITÉRIO DAS ESPECIFICIDADES METODOLÓGICAS

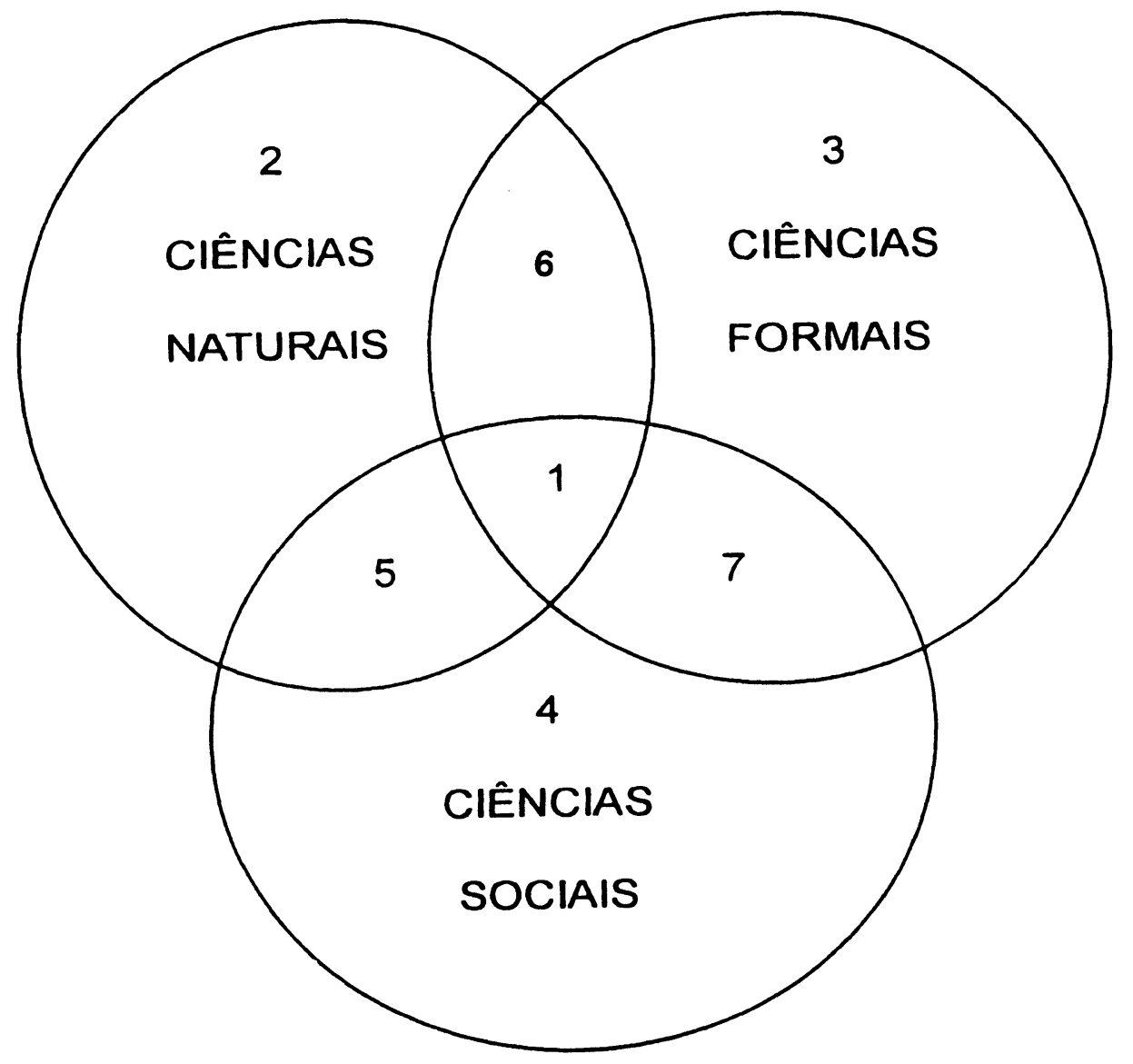

Fonte: OLIVEIRA FILHO $(1987$, p. 2).

Segundo o referido autor, na região 1 encontram-se as distinções conceituais e regras metodológicas mais abstratas comuns às várias ciências caracteristicas, portanto, de uma "Metodologia Geral". Tratam-se, no caso, das noções da lógica elementar que atingem inclusive a linguagem ordinária como, por exemplo, termo, sentença, argumento, validade, verdade, operação do cálculo sentencial. Nas regiōes 2,3 e 4 estão as noções e regras metodológicas 
específicas, próprias portanto de cada disciplina cientifica, consideradas as diferentes abordagens teórico-metodológicas que comportam. A estas o autor nomeia como "Metodologias Diferenciais ou Especiais". Afirma que no caso das Ciências Sociais, que é seu objeto de preocupação, estas regras apresentam uma relação profunda entre metodologia e teorias sociológicas. Finalmente, em 5, 6 e 7 encontram-se as regiões que caracteriza como de colaboração entre posturas teórico-metodológicas e denomina de "Metodologia Fundamental ou Comparada".

\section{ACERCA DE DESAFIOS METODOLÓGICOS}

Ao se pensar a questão da inscrição da Saúde Pública ou Coletiva no conjunto das Ciências Naturais, Sociais e Formais, especificadas via diagrama de Venn-Euler por OLIVEIRA FILHO (1987), não somente as características definidoras do campo se evidenciam, como as questões metodológicas daí decorrentes se apresentam mais explicitamente.

Como aspecto básico destaca-se o fato de esta não se constituir numa disciplina que pertença ao campo das Ciências Naturais ou das Ciências Sociais. Caracteriza-se antes como uma interdisciplina científica cuja área empírica é passivel de ser explorada pelos dois grupos de ciências, as naturais e as sociais atuando, as formais, como apoio.

Outro aspecto relevante é a de que pelas especificidades do campo e natureza bio-psicossocial de seu objeto - caracterizado pelos processos de saúdedoença-morte de natureza coletiva - a Saúde Pública comporta o trabalho interdisciplinar em diferentes níveis, além do tratamento de temas especificos por diferentes disciplinas, de diferentes áreas, com diferentes abordagens. Neste âmbito colocam-se quer as questőes ontológicas, relativas às diferentes maneiras 
de se conceber a natureza do objeto, quer as epistemológicas, decorrentes dos diferentes tipos de análise.

Considera-se que em função dessas características as questōes metodológicas que se apresentam ao campo da Saúde Pública sejam mais desafiadoras do que em outras áreass disciplinares na medida em que o mesmo deve responder pela diversidade de seu objeto, contemplar diferentes niveis de análise e caracterizar-se como amplo campo científico voltado quer ao conhecimento do processo saúde-doença-morte, quer ao conhecimento do processo de intervenção.

Dado que os paradigmas ou tradições de pesquisa vigentes não dão conta dos vários problemas emergentes, que se localizam à margem da chamada "ciência normal", o grande problema metodológico que se coloca ao campo é o da necessidade de adoção ou criação de novos esquemas teórico-metodológicos de explicação, ao lado de novo arsenal tecnológico. Para tanto, o concurso do trabalho disciplinar, de diferentes áreas, e interdisciplinar - que inclui o próprio filósofo da ciência - coloca-se como altamente relevante.

Em relação a este último, um dos desafios metodológicos típicos pode ser observado quando da busca de análise de algumas questões como, por exemplo, a da articulação dos diferentes niveis de determinação do processo saúde-doença ou a das relaçōes entre crescimento e desenvolvimento infantil. Por pressuporem 0 concurso de várias disciplinas cientificas, 0 conhecimento interdisciplinar de tais problemas passa a requerer sobretudo o aprofundamento teórico-metodológico nas áreas de interface entre as Ciências Naturais e as Ciências Sociais, caracterizadas por OLIVEIRA FILHO (1987) no diagrama de Venn-Euler, como regiões das Metodologias Fundamentais ou Comparadas. $\mathrm{Na}$ medida em que $\circ$ trabalho interdisciplinar contempla nesse nivel a elaboração de 
novos esquemas de análise, tal empreendimento intelectual passa a exigir do cientista a incursão no campo da Filosofia da Ciência tendo em vista a necessidade de fundamentar as teorias e os métodos e técnicas de pesquisa empregados.

Nesse sentido é que a metodologia, como disciplina metateórica, passa a ser vista como fundamental dada a sua função reorientadora que permite importantes intervenções na atividade cientifica sobretudo em campos de natureza multidisciplinar como é o da Saúde Pública.

\section{REFERÊNCIAS BIBLIOGRÁFICAS}

1. AYALA, F. J. \& DOBZHANSKY; ed. Estudios sobre la filosofia de la biologia. Barcelona, Editorial Ariel, 1983.

2. BRE.ILH, J. \& GRANDA, E. Investigación de la salud en la sociedad: guía pedagógico sobre un nuevo enfoque del método epidemiológico. Quito, Ed. CEAS, 1980.

3. BRUYNE, P. et al. Dinâmica da pesquisa em ciências sociais: os polos da prática metodológica. 3 ed., Rio de Janeiro, Ed. Francisco Alves, (1982)

4. EWING, A. C. As questões fundamentais da filosofia. Rio de Janeiro, Zahar Ed., 1984., p. 50-64: A Verdade.

5. GARCIA, J. C. Medicina e sociedade: as correntes de pensamento no campo da saúde. In: NUNES, E. D. org. - Medicina social: aspectos históricos e teóricos. São Paulo, Global Ed., 1983., p. 96-131. Textos 3.

6. KAPLAN, A. The conduct of inquiry: methodology for behavioral science. 1964, Apud BRUYNE, P. et al. Dinâmica da pesquisa em ciências sociais: os polos da prática metodológica. 3 ${ }^{\underline{a}}$ ed., Rio de Janeiro, Ed. Francisco Alves, 1982, p. 26.

7. KUHN, T. A estrutura das revoluções cientificas. São Paulo, Ed. Perspectiva, 1975. 
8. LAURELL, A. C. La salud-enfermedad como proceso social. Cuad. Med. Soc., (19): $7-20,1982 b$.

9. OLIVEIRA FILHO, J. J. Reconstruções metodológicas de processos de investigação social. Rev. de História, 54(107): 263-76, 1976.

10. OLIVEIRA FILHO, J. J. Curso de metodologias das ciências sociais: Notas de aula. São Paulo, 1987. [Curso de Ciências Sociais da Faculdade de Filosofia, Letras e Ciências Humanas da Universidade de São Paulo]

11. POPPER, K. Lógica da pesquisa científica. São Paulo, Ed. Cultrix, 1972.

12. SKOLIMOWSKI, H. Problemas de racionalidad en biologia. In: AYALA, I. J. \& DOBZHANSKI, ed. Estudios sobre la filosofia de la biologia. Barcelona, Ed. Ariel, 1983. p. 267-291.

13. WARTOFSKY, M. W. Introducción a la filosofia de la ciencia. $2^{\text {a }}$ ed., Madrid, Ed. Alianza Universidad, 1976. 1, cap. 1 (Ciência y Filosofia: introducción).

14. WHITE, M. A explicação histórica. In: GARDINER, P. org. Teorias da história. $2^{\underline{a}}$ ed., Lisboa, Fundação Calouste Gulbenkian, 1974, p. 436-456. 